
\title{
Research S Surare \\ Identifying Priorities, Directions and a Vision for Indigenous Mental Health Using a Collaborative and Consensus-Based Facilitation Approach
}

Stephanie Montesanti ( $\sim$ montesan@ualberta.ca )

University of Alberta https://orcid.org/0000-0002-3284-5767

Kayla Fitzpatrick

University of Alberta

Bryan Fayant

McMurray Métis Local

Caillie Pritchard

University of Alberta

\section{Research Article}

Keywords: Indigenous mental health, mental health service delivery, cultural-safety, health policy, multisectoral collaboration, community visioning, priority setting, nominal group consensus method

Posted Date: May 5th, 2021

DOl: https://doi.org/10.21203/rs.3.rs-460559/v1

License: (9) (1) This work is licensed under a Creative Commons Attribution 4.0 International License. Read Full License

Version of Record: A version of this preprint was published at BMC Health Services Research on March 27th, 2022. See the published version at https://doi.org/10.1186/s12913-022-07682-3. 


\section{Abstract}

\section{Background}

Mental health disparities between Indigenous and non-Indigenous people in Canada are related to underlying economic, social and political inequities that are legacies of colonization and the oppression of Indigenous cultures. It also widely acknowledged that mental health services currently available may not be culturally appropriate in supporting the health needs of Indigenous Canadians. A two-day Indigenous mental health forum examined mental health needs and gaps among Indigenous communities across the Regional Municipality of Wood Buffalo (RMWB) on Treaty 8 territory, in northern Alberta, Canada. Specifically, the forum's aims were to: 1) discuss the challenges and opportunities in addressing mental health among Indigenous youth, adults, and families; 2) network key stakeholders from the RMWB to explore where sectors could overlap and collaborate on improving mental health services for Indigenous populations; and 3) create recommendations to support Indigenous peoples' mental health and wellness across the life course.

\section{Methods}

We applied a modified nominal group consensus method embedded within Indigenous knowledge to determine key priorities and directions for Indigenous-focused mental health and synthesize information from discussions that occurred at the forum. The principles of two-eyed seeing were used with the goal of responding to and resolving conflicts between Indigenous ways of knowing and western scientific inquiry that informs mental health services.

\section{Results}

Four key themes for setting priorities and directions for Indigenous mental health emerged from roundtable group discussions. 1) understand the realities of mental health experiences for Indigenous peoples, 2) design a holistic and culturally-rooted mental health system, 3) foster cross-sectoral engagement and collaboration on mental health service delivery, and 4) focus on children and youth. On day two of the forum, a participatory community visioning exercise was facilitated during which participants collectively created a community vision for an Indigenous-led mental health response for the RMWB.

\section{Conclusions}

Forum participants described mental health and well-being around holistic concepts of social and emotional well-being. Addressing Indigenous mental health and wellness involves multi-sectoral action in various settings including community and school through programs, policies and other interventions that promote mental health for all Indigenous peoples, as well as for those at greater risk such as children and youth. 


\section{Background}

Mental health can be influenced by traumatic early life exposures, leading to greater risk of long-term stress and mental illness in some individuals $(1,2)$. Although disproportionate burden of mental illness among Indigenous people has been attributed to the intergenerational impact of colonization, others have acknowledged that services currently available may not be culturally appropriate in supporting the health needs of Indigenous peoples (1).

For many Indigenous residents and communities in the Regional Municipality of Wood Buffalo (RMWB) in northern Alberta, Canada, the collective intergenerational trauma of colonization and persistent racism, together with a natural disaster and the recent COVID-19 global pandemic, has produced combined effects on mental health. The 2016 Horse River wildfire in the RMWB resulted in community destruction and displacement, loss of homes, jobs, finances, lives as well as injuries and separation from loved ones. Nearly five years post-wildfire, many individuals continue to be impacted by the social, emotional, and psychological difficulties as a result of the aftermath of the wildfire. In addition, stress and isolation from the COVID-19 pandemic in the region have also contributed to increased mental distress (3). There have been reported increases in suicide, depression, drug and alcohol use across the region, resulting from community lockdowns and the temporary unavailability of needed mental health and addictions services and supports (4). Furthermore, the COVID-19 pandemic and the actions to eliminate or mitigate it, have far-reaching social and economic consequences that are likely to disproportionately impact Indigenous communities and exacerbate mental health inequities.

The RMWB is located in a northern region of the province of Alberta and on Treaty 8 Territory, which encompasses a landmass of approximately 840,000 kilometres and home to 39 First Nations communities across the provinces of Alberta, Saskatchewan, British Columbia, and the Northwestern Territories. The RMWB is home to five First Nation communities (Mikisew Cree First Nation, Athabasca Chipewyan First Nation, Fort McKay First Nation, Fort McMurray First Nation, Chipewyan Prairie Dene First Nation), and lies within the Métis Nation of Alberta (MNA) Regions 1 and 51, and includes five Métis Locals located in Fort McMurray, Anzac, Fort Chipewyan, Fort McKay and Conklin.

In the summer of 2019, a two-day Indigenous mental health forum was hosted in June by University researchers and local Indigenous organizations from the RMWB. The purpose of the forum was to examine mental health needs and gaps among Indigenous residents and communities in the region, identify community-derived strategies for promoting mental health, and co-create a vision for improving mental health services for the Indigenous population. Using collaborative and consensus-based facilitation approaches, participants were invited to generate priorities and directions for Indigenous mental health for the RMWB. Specifically, the forum's aims were to: 1) discuss the challenges and opportunities in addressing mental health among Indigenous youth, adults, and families; 2) network key stakeholders from Wood Buffalo to explore where sectors could overlap and collaborate on improving mental health services for Indigenous populations; and 3) create innovative recommendations to support mental health wellness for Indigenous populations across the life course. This paper outlines the process 
and insights generated by stakeholder engagement at the forum to identify and prioritize directions for Indigenous mental health and build a vision and strategy for improving mental health services and programs for the region's diverse Indigenous population.

\section{Indigenous Peoples' Historical and Contemporary Experiences with Access to Mental Healthcare}

Mental health disparities between Indigenous and non-Indigenous people in Canada are related to underlying economic, social and political inequities that are legacies of colonization and the oppression of Indigenous cultures - now recognized as "cultural genocide" by the Truth and Reconciliation Commission (TRC) of Canada (5). The mental health status of Indigenous peoples in Canada must therefore be understood within the context of current and historical colonial experiences, from the loss of land and autonomy, to the creation of the reserves systems, the historical removal of Indigenous children into residential schools, the current removal of Indigenous children by the child welfare system, and systemic and epistemic racism in healthcare settings $(1,2)$.

Inequitable access to healthcare is influenced by the complexity of multiple governing bodies overseeing health care delivery, with lack of jurisdictional coordination leading to gaps in care and disparities in funding and data collection within Indigenous populations $(6,7)$. Remote communities face a lack of service providers, lack of health infrastructure and services, and high costs (7). While lack of sufficient number of mental health professionals is a concern across Canada (8), accessibility and availability of mental health care is particularly lacking for Indigenous populations, especially those in rural, remote and northern settings. Scholars have pointed to the absence of a national Indigenous mental health strategy and subsequent lack of funding as barriers to recruiting mental health professionals in rural and remote Indigenous communities and to providing culturally-competent mental services (9). Additionally, different Indigenous groups in Canada, such as Métis $(6,10)$ and urban or off-reserve First Nation communities, can have unique experiences that are often excluded in research and data, and which may require different culturally-based responses. Indigenous people also face many structural barriers due to the legacy of colonialism in a healthcare system where western knowledge is valued over Indigenous knowledge, trauma-informed care is not consistently practiced, and negative bias from care providers persists due to lack of cultural competency $(6,11-13)$.

Given the context of historical trauma and ongoing discrimination faced by Indigenous people, culturallyappropriate mental health services are imperative $(7,14)$. Self-determination is a key determinant of health for Indigenous individuals and communities. $(8,15)$. Self-determination is understood as the individual and collective right to have control over health, education, and economic systems (16). In this sense, self-determination shapes health care experiences for Indigenous peoples.

Many Indigenous communities' perspectives on health are wholistic and centered on a connection to culture $(17,18)$. Research has supported the importance of mental health clinicians practicing multicultural competence when working with Indigenous peoples, which includes acknowledging and understanding the social and cultural realities of Indigenous peoples and addressing the cultural and historical impacts of colonization (19). The strengthening of cultural and community connectedness has 
been recommended for improving mental health services provided to Indigenous peoples (19). Consultation with Elders by Drost (20) provided perspectives on how Alberta Health Services (AHS) -a provincial health authority - can expand their traditional Indigenous healing practices, which included enhancing cultural competency training for staff, and creating and maintaining partnerships with Indigenous communities.

The use of collaboration and teamwork has also been proposed to improve mental health services for Indigenous peoples. While the inclusion of Indigenous Elders within mental health services was suggested in the TRC, few health systems have attempted to integrate this, though some research projects have noted preliminary success $(21,22)$. Restoule, Hopkins $(23)$ emphasized the need to build partnerships between governments and Indigenous communities in order to continue building mental wellness, and supported the creation of multidisciplinary Mental Wellness Teams that included Elders as part of a team with community workers, social workers, psychiatrists, and other health professionals. However, more research is needed to understand opportunities and barriers for Indigenous health practitioners (11), and to fill the gap in knowledge regarding integration of Indigenous mental health workers and Indigenous Elders to provide mental health care. In order to truly have culturally-appropriate mental health programs and policies $(10,24)$, Indigenous communities need to be involved in research and consulted throughout policy-making, and receive adequate funding for mental health services. Moreover, needed transformations identified in the TRC Calls to Action for mental health include: 1) eliminating health care resource disparities; 2) ensuring culturally safe services free of racism;3) building provider capacity to effectively support healing by addressing impacts from multigenerational adverse life experiences; and 4) engaging Indigenous people within systems so that inclusion of diverse Indigenous cultures and wellness practices may promote optimal outcomes (25).

\section{Methods}

Our study followed a community-based participatory research (CBPR) approach (26) to support engagement with communities, health professionals, and leaders across the sectors in the RMWB. The objectives and plan for the Forum were developed in partnership with a Community Advisory Committee. The committee was comprised of Indigenous and non-Indigenous health service providers, as well as representation of Indigenous Elders from First Nation and Métis ancestry, including Dene-speaking and Cree-speaking members residing in the RMWB. The research team engaged the Community Advisory Committee in identifying the objectives and purpose of the forum, group discussion questions, and the facilitation and dialogue approach to ensure that Indigenous knowledge is valued and balancing power relationships among community, service providers and researchers $(27,28)$.

Representation at the forum spanned across multiple sectors to include Indigenous leadership, community service providers, mental health professionals, school teachers, representatives from the Fort McMurray School District, Indigenous Elders, youth residing in the urban and rural communities, representatives from provincial and local organizations with mandates for Indigenous Health and 
Wellness, and non-Indigenous health care, academic, and research organizations. In total, fifty-three ( $\mathrm{N}=$ 53) stakeholders from various organizations (Table 1) attended the forum.

Collaborative and consensus-based facilitation approaches can be utilized to provide a structured environment in healthcare when there is a lack of understanding and conflicts on a particular topic (29). We applied a modified nominal group method embedded within Indigenous knowledge to determine key priorities and directions, and synthesize information from discussions that occurred at the forum (29). The method employed embodies the principles of two-eyed seeing $(30,31)$, with the goal of responding to and resolving conflicts between Indigenous ways of knowing and western scientific inquiry that informs mental health services. While the nominal consensus method is a western paradigm, it has been suggested that it can be responsive to Indigenous knowledge and allows space to share a variety of perspectives to reach consensus on the topic in question $(29,32)$. The nominal group method is described as a process commonly used to gather qualitative information being used within health planning (33). Participants were invited to generate and prioritize key directions for Indigenous-focused mental health for the RMWB in roundtable groups. Roundtable discussions were guided by the following questions:

1. What matters most to you in promoting mental wellness for Indigenous youth, families, or communities?

2. What mental health resources are critical to advocate for in your community or within your organization?

3. How do current mental health services or programs address the root social causes (e.g., poverty, racism, housing, geography, etc.) of poor mental health? How might services or programs be strengthened for Indigenous clients?

4. How can the different sectors (e.g., health, education, justice) collaborate to support mental health and wellness among Indigenous peoples?

On day one of the forum, participants were divided into four roundtable groups to explore each above question. Each small group had its own discussion facilitator. Participants were asked to rotate across the four table groups, having an opportunity to contribute to discussions for all four questions. As the first step, participants were invited to silently reflect and generate directions on provided cue cards following the facilitator's posing of the question. Next, participants were invited to share, discuss and explore their proposed directions. Facilitators employed both open discussion and talking circle approaches to ensure all participants had opportunity for input. Notes were taken by facilitators during the conversation which were also audio recorded and transcribed with the verbal permission from participants. At the end of day one, facilitators from each group reported back key messages or insights that were shared at their groups. Following each roundtable discission, facilitators collected all cue cards from participants and sorted them according to emerging themes and displayed the cue cards by theme on the wall. 
On day two, using a modified Dotmocracy method as means of promoting transparency of idea sharing and ranking, and of being inclusive of diverse stakeholder voices, participants were then invited to review, reflect and vote on the priorities and directions they felt were the highest priority for each of the cue cards displayed on the wall. Participants were provided red stickers for each display area to cast their votes. Red stickers were placed next to ideas that they felt were priorities. Dotmocracy is a consensus-building method that uses a democratic voting procedure to provide a structured approach to decision-making (34). The method promotes transparency by allowing participants to observe the development of priorities around a topic or issue (35). Following the dotmocracy exercise, participants gathered to cocreate a community vision for developing an Indigenous mental health strategy for the RMWB (See Additional File 1 for graphic recording on community vision). This was done using a participatory community visioning exercise $(36,37)$ with three parts: a) developing the vision, b) defining the guiding principles, and c) identifying strengths and the components of an action plan to develop an Indigenous mental health strategy. The visioning exercise helped stakeholders to visualize a direction or path forward for addressing existing gaps in the mental health system and opportunities for strengthening Indigenous mental health in the region.

\section{Data Analysis}

The initial analysis was initiated by the roundtable group facilitators who organized the cue cards into emerging themes. Following the forum, the lead author reviewed the recordings and transcripts from roundtable discussions and the preliminary themes to develop a framework for priorities and directions for Indigenous mental health for the region (see Tables 2-4). The final analysis was presented to the Community Advisory Committee for feedback and confirmation of the key themes.

\section{Results}

\section{Priorities And Directions For Indigenous Mental Health}

From the four roundtable questions posed to participants, numerous themes emerged for setting priorities and directions for Indigenous mental health. The ideas participants jotted down on cue cards were then categorized into four broad themes: a) understand the realities of mental health experience for Indigenous peoples, $b$ ) design a holistic and culturally-rooted mental health system, c) foster crosssectoral engagement and collaboration, and d) focus on the mental health of children and youth (Tables 2-5). The themes are presented below with a short description and example quotes are presented in Tables 2-5.

\section{Theme 1: Understand the Realities of Indigenous Mental Health Experience}

Several key concepts from this theme were discussed in roundtable groups which included gaps in mental health services, the need for provider education, a focus on destigmatizing mental health, and the 
inclusion of Indigenous voices in the design and delivery of mental health services. Addressing the gaps in mental health services was described by attending to experiences with accessing mental health services or supports for Indigenous peoples. Gaps to be addressed included the need for increased frequency, consistency, and availability of mental health services in rural communities; improved transportation to access services; offering of services in Indigenous languages; and reducing system barriers by providing additional funding for mental health professionals to increase time spent in communities and with clients in rural and remote settings. For education, the importance of mental health providers understanding the context and experience of Indigenous peoples was emphasized. This included a need for providers to understand the history of Indigenous peoples and the lasting impacts from colonialism on intergenerational trauma, and to understand the social determinants specific to Indigenous peoples that play an important role in their health. Participants emphasized that this requires more than just cultural sensitivity training or certification it involves changing how care is provided at the institutional level to provide supportive and safe environments for Indigenous clients. Tied to the gap of funding for providers, the need for sufficient time with Indigenous clients was discussed as a component of building trusting provider-client relationships and better allowing providers to gain a deep understanding of the root social causes of health inequities. For destigmatizing mental health, participants suggested changing the way it is discussed, with the possibility of a more positive framing emphasizing health rather than illness. The idea of removing stigma and introducing empowerment for individuals to understand mental health and wellness was also introduced. The inclusion of Indigenous voices in the design and delivery of services was highlighted by participants and in particular, engagement and involvement of Indigenous Elders in the design and delivery of services. Participants also emphasized the importance for providers and government to understand what healing and wellness means to Indigenous peoples, and for communities to drive the focus of mental wellness through Indigenous-led programing and service delivery.

\section{Theme 2: Design a Holistic and Culturally Rooted Mental Health System}

The key concepts under this theme focused on the inclusion of Indigenous peoples in health system decision-making, as well as harnessing resources within local communities using a strengths-based approach. In addition, providing culturally appropriate and trauma-informed care was highlighted as critical for mental health service provision in the region. Allocating funding to train and hire Indigenous mental health workers from the communities was suggested as this could build local capacity and provide cultural support and traditional healing practices to clients. This also encourages programs and services to focus on strengths that are already within communities. Furthermore, including traditional knowledge in the delivery of mental health services was deemed necessary for supporting culturally appropriate care. Participants also spoke about promoting culturally-strengthening factors, such as connection to family and kinship and "bringing back what has been lost" as a result of dominant western approaches to treatment - such as, traditional healing practices, Indigenous language and Indigenous knowledge. Multiple areas for Elders or Knowledge Keepers to be engaged were identified as 'cultural mentors' in the training of mental health professionals, in schools to teach youth about mental wellness 
through cultural and traditional practices, and in paid positions working alongside western health providers for home visits. Moving away from the medical model of sickness and instead including Indigenous knowledge frameworks, such as the Medicine Wheel, was recommended for a holistic approach to healing that is focused on the 'whole person'. One participant shared that if we are not open to new ways of doing things, then the health system and people working within the system "will remain stuck in this perpetual state of doing the same thing over and over that doesn't work." Participants also explained that the way the mental health system works now, with mental health professionals using individualized approaches and solutions, is not aligned with an Indigenous holistic view of health and wellness. The holistic approach would take into consideration the individual, family, and community needs to promote healing and recovery. Additionally, the need for cultural sensitivity across the spectrum of mental health care, from prevention to promotion, was also identified. When discussing traumainformed care, the embedding of Indigenous culture and values into treatment and healings was described. Other recommendations included the provision of addiction and counselling supports across an individual's lifespan, and the acknowledgment and implementation of the TRC commitments on health across organizations.

\section{Theme 3: Foster Cross-Sectoral Engagement and Collaboration}

The key concepts within this theme that emerged from participant discussions included providing wraparound care, addressing the social determinants of health, collaboration between agencies and sectors, and educating across sectors. From roundtable discussions participants emphasized that the basic needs of individuals have to be supported in order to achieve positive mental health. In order to provide comprehensive holistic support that includes meeting Indigenous peoples' basic needs (e.g., housing, food security, shelter, safety, community, social support, health services), organizations need to regularly work collaboratively. Establishing a sustainable long-term interagency committee or board that coordinates the different sectors was suggested by participants as a way to foster collective understanding and collaboration among the sectors on mental health service delivery. It was also mentioned that the sectors also need to be decolonized through education regarding past historical trauma and by implementing systemic changes that prioritize anti-racism and culturally safe environments to provide mental health care. Also, participants offered valuable insights for how mental health services and programs can be strengthened for Indigenous clients. They encouraged service organizations, funders, decision makers and health care professionals to carefully consider the 94 Calls to Action from the TRC of Canada. Upstream innovations require that high quality and culturally-resonant services inform structural and policy changes to ensure that Indigenous-focused mental health is responsive to diverse community needs and priorities. The TRC Calls to Action also propose areas for transformation across service sectors (e.g., child welfare, education, justice, health), and compel institutions to explore what achieving needed transformation may require in terms of collaboration, resource allocation, inclusion and capacity-building of Indigenous people and non-Indigenous partners at all levels. 
The justice sector also has a role to play, with the suggestion for promoting restorative justice that is more in line with traditional Indigenous views of healing and rehabilitative justice. Restorative justice is an approach which brings together the victim, the offender, members of the larger community, and often times professional service providers into a non-hierarchal setting in order to collectively address a harm that was committed and to set a path towards reconciliation between all parties involved $(38,39)$. Some participants spoke about acknowledging and bringing forward Indigenous legal traditions. Indigenous legal approaches to crime and addressing harm contain principles and mechanisms that can be described as promoting community healing, reconciliation, and the reintegration of the offender.

\section{Theme 4: Focus on Children and Youth}

The key concepts for child and youth mental health included making early investments in children's health and social development, engaging parents and families, promoting youth mentorship, and providing culturally appropriate counselling services for Indigenous youth. The need for supports throughout the lifespan was emphasized, as supporting healthy early childhood development begins during pregnancy and infancy. Family engagement and mentorship and the inclusion of parents and families in the school and children's learning as well as the involvement of Elders and peers as mentors was identified as part of healthy families and the holistic model of health. Family-Centered Care (FCC) involves working in partnership with a family and caring for children and youth in the context of their family. Indigenous peoples believe caring for children is the shared responsibility of their communities. Therefore, participants described the importance that programs or services honor traditional beliefs of wellbeing and parenting practices. However, exclusionary social policies across Canada have to varying degrees disrupted family relations. Some participants went on to share that a traditional way of life taught children the importance of connectedness to family and their nation, whereas contemporary society and the education system has taught us about isolation and individual gain. This lost sense of connection and belonging has then resulted in a loss of purpose, pride and identity. When considering existing gaps in the mental health system, participants noted that there is a lack of specialized care and supports for children and youth. Thus, dedicated and specialized mental health services for Indigenous children and youth was considered critical, and should involve all sectors (health, education, community and justice) to work together.

\section{Community Visioning}

From the participatory exercise on Day Two of the forum, a vision for the community was formed (see Additional file 1 and Additional file 2 for graphic recordings of community vision). The community vision created by participants include core guiding principles: taking a strengths-based perspective; respecting Indigenous knowledge; and breaking down the stigma of mental health. There was consensus that the design and delivery of mental health services should take a strengths-based approach to promote mental wellness among Indigenous residents and communities in the region. Focusing on the positive was also discussed in the context of existing data on mental health outcomes in Indigenous population that is often used to inform service delivery or policies is deficit focused. Additionally, participants voiced that Indigenous-led health partnerships and services are grounded in traditional Indigenous knowledge - 
upheld by community Elders - rather than being grounded in Western medicine, structures and knowledge.

\section{Discussion}

The two-day Indigenous mental health forum led to the identification of priorities and directions for Indigenous mental health in the northern region of Alberta, Canada. The research team, community leaders, service providers, and decision-makers came together to build a vision for improving mental health services and programs for the region's diverse Indigenous population. Participants envisioned a holistic and integrated mental health model that is Indigenous-informed and culturally-based, and grounded in community-led mental health and wellness services that blends Western modalities with Indigenous knowledge and healing practices $(11,40)$. Given the importance of traditional healing practices and culturally appropriate care for Indigenous people, it is critical that these sources of healing are integrated into their care. Moreover, an integrated care model utilizes the strengths and collaborative skills of many health professionals and specialists, as well as collaboration with patients, families and caregivers (41). Participants also mentioned that existing mental health services and funding should be realigned to build a more culturally-based system of mental health services. With regards to having more Indigenous people educated in the mental health profession, Indigenous communities are already employing Indigenous methods and approaches and engaging Elders and knowledge keepers, and healers to support system transformation within the area of health (22). The training and hiring of Indigenous people within the mental health profession to support holistic mental health service delivery was identified as a key priority by participants for supporting their vision towards Indigenous-led, culturally-safe and equitable mental healthcare in the region.

The COVID-19 pandemic has also highlighted vulnerabilities in local workforces that are highly dependent on staff from out of community. Long-term initiatives to build local capacity are needed, given the significant issues which have arisen in relation to available workforce (including the need to isolate fly-infly-out staff and local Indigenous staff who are unable to work). There is a need to ensure Indigenous health workers are supported to provide the best care for communities, especially in areas with preexisting staff shortages. The training of Indigenous health workers will help reduce the reliance on out-ofcommunity health practitioners providing services to remote and rural communities and more importantly, address surge workforce planning in Indigenous and rural communities in anticipation of future outbreaks of COVID- 19 and the associated mental health and social impacts.

Participants advocated for holistic approaches to mental health delivery for Indigenous people. Individualized approaches to mental health exclude the family and kinship networks that support the individual's healing journey. Rather, holistic approaches to mental health need to look at the individual's mental health state and experience within the context of their family and community structure. Therefore, family and kinship networks should be involved in the person's healing journey. Participants further explained that the utilization of the medicine wheel can serve as a framework for improving the mental health and wellbeing of Indigenous people in the region. The medicine wheel is used to explain an 
Indigenous worldview of life. It is a symbol that represents the connectedness of everything in life. All four elements interact together to form a strong, healthy person. The medicine wheel can also be used to guide transformation of mental health services.

Championing self-determination was also highlighted as an important factor in the development of Indigenous mental health services. The TRC Call to Action \#22 states, "We call upon those who can effect change within the Canadian health care system to recognize the value of Aboriginal healing practices and use them in the treatment of Aboriginal patients in collaboration with Aboriginal healers and Elders where requested by Aboriginal patients" (5). This highlights the need for self-determination in use of traditional knowledge and healing practices which have persevered despite systemic oppression and colonial policies. There are several examples in Canada of Indigenous-led and Indigenous-driven mental health initiatives that promote Indigenous knowledge, culture and language. It was clearly identified during the roundtable group discussions that mental health services and supports must be driven by the needs and priorities identified by communities. Services must also target clearly identified measures of wellness. A systematic literature review (6) found that mental health services developed by Indigenous communities were the most effective at providing appropriate care. Co-creating Indigenous models of care with Indigenous communities has also been recommended to support self-determination, increased community participation in health, and increased community capacity (40). Maar, Erskine (9) found that a collaborative, community-based Indigenous mental health care model led to improvements in culturallysafe care for Indigenous communities in northern Ontario, Canada. Also, Kyoon-Achan, Philips-Beck (42) created a framework for mental wellness that was co-developed with Indigenous communities to include culturally-informed approaches, allowing participants to articulate their experiences and to advocate for and support culturally-informed mental health services. Therefore, this is growing evidence towards Indigenous-led health care partnerships for improving health outcomes and access to care for Indigenous peoples (12).

Participants at the forum highlighted that the different sectors need to be open and willing to explore different ways or models of delivering mental health services that is inclusive of different knowledge systems on health (i.e., both western and Indigenous knowledge), healing practices and the preferences of Indigenous clients. Mental health promotion requires multi-sectoral action across health, education, community and the justice sectors, and through the delivery of culturally-safe, strengths-based, family and community-oriented mental health and wellness programs, services and policies that aim to promote healthy emotional, spiritual and social development in childhood and adolescence; as well as those at risk of poor mental health $(43,44)$. More importantly, mental health experiences and strengths vary among Indigenous communities and individuals and this variation reflects the distinctiveness of First Nations, Métis and Inuit peoples' histories, languages, cultures, environments and worldviews.

Stigma and discrimination remain a barrier to accessing mental health services for many Indigenous peoples in Canada $(13,45)$. The values and traditions of Indigenous persons may be poorly understood and their concepts of wellness and ways of knowing sometimes undervalued. Moreover, decolonizing mental health is more than just practicing cultural competence - the ability to understand and interact 
with people of different cultures. Instead, it is recognizing that for many Indigenous peoples the trauma from oppression and colonization plays a major role in their state of mental health.

The themes that emerged from the forum offer important insights for future research, practice and policy. Firstly, the forum was inclusive diverse perspectives from Métis and First Nations people, across urban and rural community settings. Different Indigenous groups, such as Métis $(6,10)$ and urban or off-reserve First Nations can have unique experiences that are often excluded in research and data. Secondly, the Alberta Government's 2020-2023 fiscal plan commits \$100M for a new mental health and addiction strategy. This investment is intended to address the ongoing challenges of mental health and addictions in Alberta (46). However, there is no mention of how (or if) funding for mental health services or supports will be allocated to Indigenous communities. This presents a window of opportunity to advocate for improved, equitable and culturally-resonant mental health services and programs for northern Indigenous populations in the province. Finally, The cumulative stress caused by natural disasters and the current global COVID-19 pandemic is detrimental to the mental health and wellbeing of children, youth and families (47). With the current pandemic, families are experiencing stress, anxiety, concern and even fear. This pandemic presents unique challenges for Indigenous communities across Canada, particularly Elders who are most at risk and northern and remote communities who have limited access to services and other types of supports (48-50). The pandemic has reported to compound existing mental health concerns and may bring up past or lingering trauma for Indigenous peoples who have endured past historical trauma from colonialist policies $(3,51,52)$. During this challenging time, it is important that we commit to a mental health system that is holistic as well as individual, family and community centered. Moreover, disasters and emergencies have been found to result in some positive experiences, including strengthened relationships and social networks (47). It is important that we highlight the strength and resilience of Indigenous peoples during challenging and traumatic events like a natural disaster or public health crisis. Research that examined how Indigenous residents coped after the 2016 Horse River wildfire revealed the importance of kinship, social and community support, and connection to culture as positive coping mechanisms and factors influencing mental health and wellbeing (53-56).

\section{Conclusion}

The Indigenous mental health forum was a first step towards fostering multi-sectoral and community relationship-building and collaboration on setting priorities and directions for an Indigenous mental health strategy in the RMWB. Improving Indigenous mental health requires multi-sectoral action in various settings including community and school through programs, policies and other interventions that promote mental health for all Indigenous peoples, as well as for those at greater risk such as children and youth. An Indigenous-focused model of care outlines best practice care and services for Indigenous communities and utilizes the strengths and collaborative skills of many health professionals and traditional healers. Moreover, an Indigenous-focused model of care fosters relationships and collaboration between care providers, patients, families, and caregivers (41), and ensures Indigenous knowledge, local context, equity of access, and integration of services is supported. 


\section{Abbreviations}

RMWB

Regional Municipality of Wood Buffalo

RM

Regional Municipality

MNA

Métis Nation of Alberta

TRC

Truth and Reconciliation Commission

AHS

Alberta Health Services

CBPR

Community-Based Participatory Research

FCC

Family-Centered Care

\section{Declarations}

\section{Ethics approval and consent to participate}

This research was approved by the University of Alberta Research Ethics Board (Pro00070845). Verbal consent was obtained to record and transcribe the roundtable group discussion.

\section{Consent for publication}

Not applicable.

\section{Availability of data and materials}

Data sharing is not applicable to this article as no datasets were generated or analyzed during the current study.

\section{Competing interests}

The authors declare that they have no competing interests.

\section{Funding}

The funding for the Indigenous Mental Health Forum was provided grant from the Canadian Institutes of Health Research (CIHR)'s Indigenous Healthy Life Trajectory Initiative (I-HeLTI). The views expressed in this report are the views of the participants and the authors and should not be taken to represent the 
views of the ClHR. The CIHR did not play any role in the design of the study and collection, analysis, and interpretation of data, nor in writing of the manuscript.

\section{Authors' contributions}

SM and BF worked with the Community Advisory Committee to conceptualize the forum. The forum was hosted by SM and BF. SM reviewed the recordings and transcripts from roundtable discussions and the preliminary themes to develop a framework for priorities and directions for Indigenous mental health for the region. $\mathrm{CP}$ performed a review of existing literature. $\mathrm{SM}, \mathrm{KF}$, and $\mathrm{CP}$ were all major contributors in writing the manuscript. All authors read and approved the final manuscript.

\section{Acknowledgements}

The authors would like to thank the stakeholders who participated in the Indigenous Mental Health Forum on June 24th and 25th 2019. The authors also thank Candace Sturgess for the organization of the forum, and the facilitators who supported roundtable discussions. We are thankful for the knowledge and wisdom shared by Elders and Knowledge Holders, youth, health professionals and community members. We are also grateful to the Community Advisory Committee for providing feedback on the final analysis. The authors would also like to thank Winta Ghidei for providing support on formatting and references.

\section{Authors' information}

SM holds the following positions: Associate Professor, School of Public Health, University of Alberta; Scientist, Centre for Healthy Communities, School of Public Health, University of Alberta; Member, Women and Children's Health Research Institute, University of Alberta. KF is a senior research associate at the School of Public Health, University of Alberta. BF holds the position of Disaster Recovery Strategist for McMurray Métis (MNA Local 1935). CP is a Research Assistant in the School of Public Health, University of Alberta.

\section{References}

1. Adelson $\mathrm{N}$. The embodiment of inequity: Health disparities in Aboriginal Canada. Can J Public Health. 2005;96:S45-61.

2. King M, Smith A, Gracey M. Indigenous health part 2: the underlying causes of the health gap. 2009;374(9683):76-85.

3. Jenkins EK, McAuliffe C, Hirani S, Richardson C, Thomson KC, McGuinness L, et al. A portrait of the early and differential mental health impacts of the COVID-19 pandemic in Canada: findings from the first wave of a nationally representative cross-sectional survey. Preventive Medicine. 2021;145:106333.

4. Júnior JG, Moreira MM, Pinheiro WR, de Amorim LM, Lima CKT, da Silva CGL, et al. The mental health of those whose rights have been taken away: An essay on the mental health of indigenous 
peoples in the face of the 2019 Coronavirus (2019-nCoV) outbreak. Psychiatry research. 2020; 289:113094.

5. Truth and Reconciliation Commission of Canada. Honouring the truth, reconciling for the future: Summary of the final report of the Truth and Reconciliation Commission of Canada. 2015.

6. Nelson SE, Wilson K. The mental health of Indigenous peoples in Canada: A critical review of research. Social Science \& Medicine. 2017;176:93-112.

7. Kielland N, Simeone T. Current issues in mental health in Canada: The mental health of First Nations and Inuit communities. Ottawa, Canada: Legal and Social Affairs Division: Parliamentary Information and Research Service; 2014.

8. Lints-Martindale AC, Carlson AA, Goodwin SL, Thompson SN. Putting recommendations into practice: Improving psychological services in rural and northern Canada. Canadian Psychology/psychologie canadienne. 2018;59(4):323.

9. Maar MA, Erskine B, McGregor L, Larose TL, Sutherland ME, Graham D, et al. Innovations on a shoestring: a study of a collaborative community-based Aboriginal mental health service model in rural Canada. International journal of mental health systems. 2009;3(1):1-12.

10. Auger MD. 'We need to not be footnotes anymore': understanding Métis people's experiences with mental health and wellness in British Columbia, Canada. Public health. 2019;176:92-7.

11. Rogers BJ, Swift K, van der Woerd K, Auger M, Halseth R, Atkinson D. At the interface: Indigenous health practitioners and evidence-based practice. Prince George, BC: National Collaborating Centre for Aboriginal Health; 2019.

12. Allen L, Hatala A, ljaz S, Courchene ED, Bushie EB. Indigenous-led health care partnerships in Canada. CMAJ. 2020;192(9):E208-E16.

13. Nguyen NH, Subhan FB, Williams K, Chan CB. Barriers and mitigating strategies to healthcare access in Indigenous communities of Canada: A Narrative Review. Healthcare. 2020;8(2):112.

14. Strudwick G, Sockalingam S, Kassam I, Sequeira L, Bonato S, Youssef A, et al. Digital Interventions to support population mental health in Canada during the COVID-19 pandemic: Rapid Review. JMIR mental health. 2021;8(3):e26550.

15. Auclair G, Sappa M. Mental health in Inuit youth from Nunavik: clinical considerations on a transcultural, interdisciplinary, community-oriented approach. Journal of the Canadian Academy of Child and Adolescent Psychiatry. 2012;21(2):124.

16. Auger M, Howell T, Gomes T. Moving toward holistic wellness, empowerment and self-determination for Indigenous peoples in Canada: Can traditional Indigenous health care practices increase ownership over health and health care decisions? Canadian Journal of Public Health. 2016;107(4):393-e8.

17. Stewart SL. Promoting Indigenous mental health: Cultural perspectives on healing from Native counsellors in Canada. International Journal of Health Promotion and Education. 2008;46(2):49-56.

18. Restoule BM, Hopkins C, Robinson J, Wiebe PK. First Nations mental wellness: Mobilizing change through partnership and collaboration. Canadian. Journal of Community Mental Health. 
2018;34(4):89-109.

19. Gould B, MacQuarrie C, O'Connell ME, Bourassa C. Mental wellness needs of two Indigenous communities: Bases for culturally competent clinical services. Canadian Psychology/Psychologie canadienne. 2020.

20. Drost JL. Developing the alliances to expand traditional Indigenous healing practices within Alberta Health Services. The journal of alternative and complementary medicine. 2019;25(S1):S69-S77.

21. Tu D, Hadjipavlou G, Dehoney J, Price ER, Dusdal C, Browne AJ, et al. Partnering with Indigenous Elders in primary care improves mental health outcomes of inner-city Indigenous patients: Prospective cohort study. Canadian Family Physician. 2019;65(4):274-81.

22. Hadjipavlou G, Varcoe C, Tu D, Dehoney J, Price R, Browne AJ. "All my relations": experiences and perceptions of Indigenous patients connecting with Indigenous Elders in an inner city primary care partnership for mental health and well-being. CMAJ. 2018;190(20):E608-E15.

23. Restoule BM, Hopkins C, Robinson J, Wiebe PK. First Nations mental wellness: Mobilizing change through partnership and collaboration. Can J Community Ment Health. 2015;34:89-109.

24. Isaak CA, Mota N, Medved M, Katz LY, Elias B, Mignone J, et al. Conceptualizations of help-seeking for mental health concerns in First Nations communities in Canada: A comparison of fit with the Andersen Behavioral Model. Transcultural psychiatry. 2020;57(2):346-62.

25. Truth and Reconciliation Commission of Canada. Truth and Reconciliation Commission of Canada: Calls to Action. Winnipeg, Manitoba: Truth and Reconciliation Commission of Canada; 2012.

26. Fletcher C. Community-based participatory research relationships with aboriginal communities in Canada: An overview of context and process. Pimatisiwin: A Journal of Aboriginal \& Indigenous Community Health. 2003;1(1).

27. Kendall E, Sunderland N, Barnett L, Nalder G, Matthews C. Beyond the rhetoric of participatory research in indigenous communities: Advances in Australia over the last decade. Qualitative Health Research. 2011;21(12):1719-28.

28. Baum F, MacDougall C, Smith D. Participatory action research. Journal of epidemiology and community health. 2006;60(10):854.

29. Chatwood S, Paulette F, Baker R, Eriksen A, Hansen KL, Eriksen H, et al. Approaching Etuaptmumkintroducing a consensus-based mixed method for health services research. International journal of circumpolar health. 2015;74(1):27438.

30. Marshall M, Marshall A, Bartlett C. Two-eyed seeing in medicine. Determinants of Indigenous peoples' health in Canada: beyond the social2015. p. 16-24.

31. Bartlett C, Marshall M, Marshall A. Two-eyed seeing and other lessons learned within a co-learning journey of bringing together indigenous and mainstream knowledges and ways of knowing. Journal of Environmental Studies and Sciences. 2012;2(4):331-40.

32. Crowshoe LL, Sehgal A, Montesanti S, Barnabe C, Kennedy A, Murry A, et al. The Indigenous primary health care and policy research network: Guiding innovation within primary health care with Indigenous peoples in Alberta. Health Policy. 2021. 
33. Søndergaard E, Ertmann R, Reventlow S, Lykke K. Using a modified nominal group technique to develop general practice. BMC Family Practice. 2018;19:117.

34. Hidalgo ES, editor Dotmocracy and planning Poker for uncertainty management in collaborative research: two examples of co-creation techniques derived from digital culture. Proceedings of the Sixth International Conference on Technological Ecosystems for Enhancing Multiculturality; 2018.

35. Diceman J. Dotmocracy Handbook. 2010. p.

https://library.uniteddiversity.coop/Decision_Making_and_Democracy/dotmocracy_handbook.pdf.

36. Ames S. The New Oregon Model: Envision Plan Achieve. Journal of Futures Studies. 2010;15(2):1636.

37. Cuthill M. Community visioning: Facilitating informed citizen participation in local area planning on the Gold Coast. Urban Policy and Research. 2004;22(4):427-45.

38. Cameron AJ. Restorative justice: A literature review. British Columbia; 2005.

39. Milward D. Making the circle stronger: An effort to buttress Aboriginal use of restorative justice in Canada against recent criticisms. IJPS. 2008;4:124.

40. Pepler E, Martell RC. Indigenous model of care to health and social care workforce planning. Healthcare management forum. 2019;32(1):32-9.

41. Valentijn PP, Schepman SM, Opheij W, Bruijnzeels MA. Understanding integrated care: a comprehensive conceptual framework based on the integrative functions of primary care. International journal of integrated care. 2013;13:e010.

42. Kyoon-Achan G, Philips-Beck W, Lavoie J, Eni R, Sinclair S, Avey Kinew K, et al. Looking back, moving forward: A culture-based framework to promote mental wellbeing in Manitoba First Nations communities. International Journal of Culture and Mental Health. 2018;11(4):679-92.

43. WHO. Mental health action plan 2013-2020. 2013.

44. Petek A, Novak M, Barry M. Interdisciplinary research framework for multisectoral mental health policy development. International journal of mental health promotion. 2017;19(3):119-33.

45. Kurtz DL, Nyberg JC, Van Den Tillaart S, Mills B. Silencing of voice: an act of structural violence urban Aboriginal women speak out about their experiences with health care. International Journal of Indigenous Health. 2008;4(1):53-63.

46. Alberta Treasury Board and Finance Communications. Fiscal plan: A plan for jobs and the economy. Alberta; 2020.

47. Marques de Miranda D, da Silva Athanasio B, Sena Oliveira AC, Simoes-E-Silva AC. How is COVID-19 pandemic impacting mental health of children and adolescents? International journal of disaster risk reduction : IJDRR. 2020;51:101845.

48. United Nations. The Impact of COVID-19 on Indigenous Peoples. 2020.

49. Wright T. Leaders detail concerns about COVID-19 impacts on Indigenous populations. 2020.

50. The Toronto Star. Mental health concerns in Inuit communities magnified in the time of COVID, says ITK's Natan Obed 2021 [ 
51. Sapara A, Shalaby R, Osiogo F, Hrabok M, Gusnowski A, Vuong W, et al. COVID-19 pandemic: demographic and clinical correlates of passive death wish and thoughts of self-harm among Canadians. Journal of Mental Health. 2021:1-9.

52. Bellrichard C. $93 \%$ spike in First Nations overdose deaths recorded in B.C. during COVID-19. CBC News. 2020 July 06, 2020.

53. Montesanti S, Fitzpatrick K, Azimi T, McGee TK, Fayant B, Albert L. "As a Native person in Canada you have to learn how to be strong, it's innate in us to cope": Indigenous stories of coping after a wildfire disaster in Alberta, Canada. 2021.

54. Mottershead KD, McGee TK, Christianson A. Evacuating a First Nation due to wildfire smoke: The case of Dene Tha' First Nation. Int J Disaster Risk Sci. 2020;11:274-86.

55. Felix ED, Afifi W. The role of social support on mental health after multiple wildfire disasters. Journal of Community Psychology. 2015;43(2):156-70.

56. Asfaw, McGee T, Christianson AC. The role of social support and place attachment during hazard evacuation: the case of Sandy Lake First Nation, Canada. . TEnvironmental Hazards. 2019;18(4):36181.

\section{Tables}

Table 1. Participating Organizations 


\begin{tabular}{|c|c|}
\hline \multirow[t]{17}{*}{$\begin{array}{l}\text { Provincial and local organizations with mandates } \\
\text { for Indigenous Health and Wellness }\end{array}$} & $\begin{array}{l}\text { Alberta Health Services (Wellness and } \\
\text { Recovery Services) }\end{array}$ \\
\hline & $\begin{array}{l}\text { Alberta Health Services (Community Wellness } \\
\text { Travelling Team) }\end{array}$ \\
\hline & McMurray Métis Local 1935 \\
\hline & Nistawoyou Friendship Centre \\
\hline & Conklin Community Association \\
\hline & Nunee Health Board \\
\hline & Chipewyan Prairie Dene Health Services \\
\hline & $\begin{array}{l}\text { Janvier Dene Wood Buffalo Community } \\
\text { Association }\end{array}$ \\
\hline & Critical Incident Stress Management \\
\hline & Waypoints \\
\hline & YMCA \\
\hline & Fort McMurray Public School District \\
\hline & Fort McMurray Catholic Board of Education \\
\hline & Dr. Clark School \\
\hline & Borealis Counselling Services \\
\hline & $\begin{array}{l}\text { Regional Municipality of Wood Buffalo } \\
\text { (Indigenous \& Rural Relations) }\end{array}$ \\
\hline & Canadian Red Cross \\
\hline \multirow[t]{2}{*}{ Non-Indigenous health care organizations } & Alberta Health \\
\hline & $\begin{array}{l}\text { Alberta Health Services (Mental Health } \\
\text { Promotion \& Illness Prevention Team) }\end{array}$ \\
\hline Academic and research organizations & The University of Alberta \\
\hline
\end{tabular}

Table 2. Understand the Realities of Indigenous Mental Health Experience (Theme 1) 


\begin{tabular}{|c|c|c|c|c|}
\hline \multicolumn{5}{|c|}{ Realities of Mental Health Experience } \\
\hline $\begin{array}{l}\text { Sub- } \\
\text { themes }\end{array}$ & Gaps & Education & $\begin{array}{l}\text { Destigmatizing } \\
\text { Mental Health }\end{array}$ & Indigenous Voice \\
\hline $\begin{array}{l}\text { Priorities } \\
\text { and } \\
\text { Directions } \\
\text { for } \\
\text { Indigenous } \\
\text { Mental } \\
\text { Health }\end{array}$ & \begin{tabular}{l}
$\quad$ Increase \\
frequency, consistency \\
and availability of \\
mental health services \\
in rural communities \\
(i.e., services and \\
supports should be \\
available more than \\
once a week) \\
$\quad \quad$ Include \\
transportation for \\
residents living in rural \\
and remote \\
communities to \\
access mental health \\
services in urban \\
centres \\
$\quad \quad$ Services and \\
support programs \\
need to be offered in \\
the Indigenous \\
languages (i.e., Cree, \\
Dene, Michif) \\
\multicolumn{1}{c}{ Service providers } \\
such as mental health \\
therapists who travel \\
from urban centres to \\
rural communities \\
have limited time to \\
spend with clients. \\
Additional funding \\
needed to hire mental \\
health professionals \\
that provide care in \\
rural and remote \\
communities
\end{tabular} & $\begin{array}{l}\text { Mental health } \\
\text { providers need to } \\
\text { understand the } \\
\text { history of } \\
\text { Indigenous peoples } \\
\text { and the impacts } \\
\text { from colonialism } \\
\text { on } \\
\text { intergenerational } \\
\text { trauma } \\
\quad \quad \text { Effective } \\
\text { mental health care } \\
\text { for Indigenous } \\
\text { patients is shaped } \\
\text { by a deep } \\
\text { understanding of } \\
\text { the causal } \\
\text { relationships } \\
\text { between social } \\
\text { factors specific to } \\
\text { Indigenous people } \\
\text { and health. } \\
\quad \quad \text { Land-based } \\
\text { learning and } \\
\text { exploring the lived } \\
\text { experience of } \\
\text { Indigenous peoples } \\
\text { are ways to help } \\
\text { providers to } \\
\text { understand, } \\
\text { acknowledge, and } \\
\text { identity } \\
\text { multigenerational } \\
\text { adverse life } \\
\text { experiences } \\
\text { Mental health } \\
\text { professionals need } \\
\text { to build } \\
\text { relationships and } \\
\text { trust with their } \\
\text { Indigenous clients. } \\
\text { Spending more } \\
\text { time with their } \\
\text { clients can allow } \\
\text { providers to explore } \\
\text { and understand the } \\
\text { root social causes } \\
\text { of inequities in } \\
\text { health }\end{array}$ & $\begin{array}{l}\quad \text { Empower } \\
\text { individuals to } \\
\text { understand } \\
\text { mental health } \\
\text { and wellness } \\
\text { without having } \\
\text { the stigma } \\
\text { associated } \\
\text { with mental } \\
\text { illness } \\
\quad \text { Change } \\
\text { the way we talk } \\
\text { about and view } \\
\text { mental illness } \\
\text { and health }\end{array}$ & $\begin{array}{l}\text { Community } \\
\text { needs to be } \\
\text { engaged in the } \\
\text { design of mental } \\
\text { health programs } \\
\text { and services } \\
\quad \text { Create } \\
\text { opportunities for } \\
\text { Indigenous } \\
\text { communities to } \\
\text { influence the } \\
\text { mental health } \\
\text { service delivery } \\
\text { model } \\
\quad \text { Community } \\
\text { drives the focus of } \\
\text { mental wellness, } \\
\text { not government- } \\
\text { initiated programs } \\
\text { and services } \\
\text { Engage the } \\
\text { communities to } \\
\text { understand what } \\
\text { healing and } \\
\text { mental wellness } \\
\text { means to them } \\
\quad \text { "Nothing } \\
\text { about us without } \\
\text { us" }\end{array}$ \\
\hline Participant & "consistency is having & "The workers need & "Maybe we & "we really need a \\
\hline
\end{tabular}


Quotes the same person come in and not different service organizations ...because you open up once, you want to keep talking to that same person. You don't want to have to keep telling your story over and over again..." build up the trust and rapport if they're going to work in the community. Because they're [referring to Indigenous residents] are not going to come to you. The workers are the one's that got to build that relationship." need to start talking about mental health differently and talking about brain health, so that we start to change the image of it as something that is broken and needs treatment." holistic, coordinated approach that's coming from our community members, not from me as a service provider, or a community leader, but truly at the heart of the grassroots level from our members."

Table 3. Design a Holistic and Culturally Rooted Mental Health System (Theme 2) 
Holistic and Culturally-Rooted Mental Health System

\begin{tabular}{|c|c|c|c|c|}
\hline $\begin{array}{l}\text { Sub- } \\
\text { themes }\end{array}$ & $\begin{array}{l}\text { Hiring and } \\
\text { Training } \\
\text { Indigenous } \\
\text { Mental Health } \\
\text { Workers }\end{array}$ & Engage Elders & $\begin{array}{l}\text { Cultural } \\
\text { Appropriateness }\end{array}$ & $\begin{array}{l}\text { Trauma- } \\
\text { Informed Care }\end{array}$ \\
\hline
\end{tabular}

\begin{tabular}{lll} 
Priorities & \multicolumn{1}{c}{ Allocate } & \multicolumn{1}{c}{$\begin{array}{c}\text { Engage Elders and } \\
\text { and }\end{array}$} \\
Directions & funding to train & Knowledge Holders from \\
for & Indigenous & the communities as \\
Indigenous & mental health & 'cultural mentors' to be \\
Mental & workers or & and ed in the training \\
Health & Indigenous & health professionals
\end{tabular}

mental health navigators from the communities who can provide cultural supports and traditional healing to Indigenous residents

$\quad$ Employing
people in the
community
builds local
capacity

$\quad$ Move away
from the medical
model of
wellness/sickness
to include
Indigenous ways
of knowledge on
health and
healing (i.e., use
the Medicine
Wheel)
$\quad \quad$ Reclaim
traditional healing
practices such as
native
counselling,
offering
traditional foods
(not market-
based/western
foods) in the
communities

Focus on the 'whole person' (individual, family and community needs) to promote healing

$\quad$ Cultural
sensitivity across
the spectrum of
care, from
prevention to
promotion of
mental health

Participant Quotes
"Staff or provider turn-over is a big challenge.

Providers outside of the community are going to invest very differently in a community when they don't expect to stay, because they don't put
"...and that means moving away from mainstream education simply in your classroom...and going back to our Elders, and whether that's involving Elders in a sort of formal education system or if that's Elders educating professionals, I don't know. We need to do

$\quad$ Embed
Indigenous
culture and
values into
healing and
treatments for
mental distress
- Addiction
and
counselling
services
should be
offered across
the person's
life span

Acknowledging

and

implementing

the TRC

commitments

across

organizations

$\begin{array}{ll}\begin{array}{ll}\text { "In order for the } \\ \text { health system to } \\ \text { better meet the }\end{array} & \begin{array}{l}\text { "I think we } \\ \text { need trauma- } \\ \text { informed } \\ \text { needs of }\end{array} \\ \begin{array}{l}\text { Indigenous } \\ \text { services and } \\ \text { people, first of all } \\ \text { it has to respect } \\ \text { and value }\end{array} & \begin{array}{l}\text { means we are } \\ \text { grounding our } \\ \text { supports in a } \\ \text { non- } \\ \text { judgmental, }\end{array} \\ \text { the people, the } & \begin{array}{l}\text { non- } \\ \text { language, the } \\ \text { culture, and then }\end{array} \\ \text { oppressive, }\end{array}$


down their roots [in the community]."

"Community-led, community-run facilities are needed to address mental health. We are always going to encounter turnover and lack of trust [of providers] if we don't have these services and programs embedded in our communities." that, but I think we need to look to our Elders who have that knowledge." it has to be equipped to be responsive to whatever needs that exist." "trauma informed care asks what happened to you rather than what's wrong with you."

\footnotetext{
"And we are building the capacity of our members and our residents who are there because they do have the knowledge, they have the connections and their relationships, and they do have their hearts in the community."
}

Table 4. Foster Cross-Sectoral Engagement and Collaboration (Theme 3) 
Cross-Sectoral Engagement and Collaboration

$\begin{array}{llll}\begin{array}{l}\text { Sub- } \\ \text { themes }\end{array} & \text { Wrap-around Care } & \begin{array}{l}\text { Social Determinants of } \\ \text { Health }\end{array} & \text { Collaboration Education }\end{array}$

Priorities
and
Directions
for
Indigenous
Mental
Health

\section{More wrap-}

around services

across the sectors is

needed, that is

family or individual-

oriented and

comprehensive; and

where a number of

organizations work

together to provide a

holistic program of

supports and

services for

Indigenous clients

\section{Advocate for 'whole health' - food security, shelter, safety, community and social support, and access to health services. This requires all the sectors to work together \\ - Meeting the basic needs of Indigenous peoples' first, such as housing and access to affordable foods \\ Interagency collaboration can support delivery of wrap around services and programs

$\quad$ Consistent
and ongoing
collaboration
required across
the sectors
(health,
education,
justice)

Break down the silos between the sectors by creating a safe space for decision-makers and providers across the sectors to come together to coordinate services and delivery

\author{
Decolonize \\ the sectors by \\ promoting \\ understanding \\ and \\ awareness of \\ past historical \\ trauma \\ - A \\ restorative \\ justice remedy \\ is one that \\ places the \\ emphasis on \\ healing the \\ harm done by \\ the \\ offence and \\ rehabilitating \\ the \\ offender to \\ avoid future \\ harms. Such \\ processes are \\ in line with \\ traditional \\ Indigenous \\ views of \\ justice and \\ healing
}

\section{Participant Quotes}

“...it's about sectors working together, it's about collaboration and more wraparound services between sectors. So, justice, health, education, community supports coming together."

"Like collaboration is necessary for wraparound services to happen. But it's more than collaboration, like,
"So what are the adversities of the family experiencing? Is it historical? Is it intergenerational trauma? Is it residential school? What might contribute to that? And then how can we support it? [...] knowing what these individual needs are, and then [in] the community? [...] Where are the gaps? And then how do we bring them all together? So not just looking at health, education or
"I think an important first step is the openness to explore within each sector, own biases, belief systems and prejudices that underlie how we provide services."

"Between the different sectors we can create a board to facilitate or co-facilitate
“I think it's really important to bring back what was lost. But it's also difficult for Elders and Indigenous health workers to enter into institutions or organizations that have been, were colonial" 
you know, is it a formal team approach. Is it where we have a judge let's say, who is hearing a case, can consult with a mental health professional to say, this is the case that I'm dealing with, you know, to understand the realities the individual is faced with."

"So it's about systems thinking, expanded thinking, to see the full picture and how all the systems such as education, health, justice, etc.

function... and working with allies across the systems to provide more wraparound service." justice, but the whole facet of it."

"we need to start to think outside the box and figure out ways to navigate these systems that are kind of making us feel a little bit inside a box...we need to be open to offering services in different ways."

"It's being able to trust the other agencies and work together collaboratively to communicate, so that in times of need or when you need that

information, you can reach out to other services, like child services and say hey, this is what I need. But in order for that to happen, there has to be a trust in the relationship."

Table 5. Focus on Children and Youth (Theme 4) 
Children and Youth

$\begin{array}{ll}\begin{array}{l}\text { Sub- } \\ \text { themes }\end{array} & \begin{array}{l}\text { Early Investments } \\ \text { (Preconception to early } \\ \text { childhood) }\end{array}\end{array}$

Engaging Parents and Families in the Schools

$\begin{array}{ll}\text { Priorities } & \text { Foster healthy childhood } \\ \text { and } & \text { development which begins } \\ \text { Directions } & \text { during pregnancy and infancy } \\ \text { for } & \\ \text { Indigenous } & \\ \text { Mental } & \\ \text { Health } & \end{array}$

\section{Participant Quotes}

"We talk about supporting early childhood development... [but] we forget that their brains are changing [like] rapid fire in their teen years... It's really important that we sustain their development throughout the years and bring in the knowledge and expertise of Elders in the school to support them [youth]..we need to provide supports throughout the lifespan."

"So when you experience relationship violence or gender-based violence...and we know that if youth are experiencing violence then they are likely going to continue that violent behaviour when their older. So we need to do a better job at intervening and creating supports and interventions so that youth who experience violence or trauma within personal relationships are not going to go on and continue those cycles of violence later in life"

$\quad$ Engage the
parents in the
school and in their
child's learning
as mentors in the
schools to support
Indigenous school-
aged children

"It's going back to that holistic model of health....we need to start with the families and the parents, that where you can do the best prevention and to create healthy children. It has to start in our communities and our homes, because that's where the wisdom and the knowledge is."

\section{Culturally Appropriate Counselling for Youth}

Mentorship

\begin{tabular}{ll} 
on Focus & \multicolumn{1}{c}{ Train } \\
specialized & youth to be \\
peer-mentors \\
counselling & in the \\
services for & schools or in \\
children and & their \\
youth in the & communities \\
schools and & \\
in & \\
communities &
\end{tabular}

“We don't have enough paediatric and youth mental health services, we simply don't... it's a greater challenge to get them to come to the rural areas, especially those specialized services"

"Education must start at home. Families, 
teach their children the culture,

how to live, how to respect,

how to treat others."

\section{Supplementary Files}

This is a list of supplementary files associated with this preprint. Click to download.

- Additionalfile1.pdf

- Additionalfile2.pdf 